\title{
Recommended diagnostic criteria for paraneoplastic neurological syndromes
}

\section{F Graus, J Y Delattre, J C Antoine, J Dalmau, B Giometto, W Grisold, J Honnorat, P Sillevis Smitt, Ch Vedeler, J J G M Verschuuren, A Vincent, R Voltz, for the Paraneoplastic Neurological Syndrome Euronetwork}

See Editorial Commentary, p 1090

J Neurol Neurosurg Psychiatry 2004;75:1135-1140. doi: 10.1136/jnnp.2003.034447

See end of article for other

members of the

Paraneoplastic

Neurological Syndrome

Euronetwork

Background: Paraneoplastic neurological syndromes (PNS) are defined by the presence of cancer and exclusion of other known causes of the neurological symptoms, but this criterion does not separate "true" PNS from neurological syndromes that are coincidental with a cancer.

See end of article for authors' affiliations

.....................

Correspondence to:

Dr F Graus, Servei de

Neurologia, Hospital

Clínic. Villarroel 170,

Barcelona 08036, Spain;

graus@medicina.ub.es

Received

23 December 2003

Revised 13 February 2004

Accepted

17 February 2004
Objective: To provide more rigorous diagnostic criteria for PNS.

Methods: An international panel of neurologists interested in PNS identified those defined as "classical" in previous studies. The panel reviewed the existing diagnostic criteria and recommended new criteria for those in whom no clinical consensus was reached in the past. The panel reviewed all reported onconeural antibodies and established the conditions to identify those that would be labelled as "well characterised". The antibody information was obtained from published work and from unpublished data from the different laboratories involved in the study.

Results: The panel suggest two levels of evidence to define a neurological syndrome as paraneoplastic: "definite" and "possible". Each level can be reached combining a set of criteria based on the presence or absence of cancer and the definitions of "classical" syndrome and "well characterised" onconeural antibody.

Conclusions: The proposed criteria should help clinicians in the classification of their patients and the prospective and retrospective analysis of PNS cases.
$\mathrm{P}$ araneoplastic neurological syndromes (PNS) were initially defined as neurological syndromes of unknown cause that often associate with cancer (table 1). ${ }^{12}$ This broad definition leaves open the possibility of considering as PNS any neurological syndrome that merely coincides with the presence of a cancer without pathogenic relation between the two disorders. In the last two decades, the discovery that many PNS are associated with antibodies against neural antigens expressed by the tumour (onconeural antibodies), has suggested that some PNS are immune mediated. ${ }^{3}{ }^{4}$ The detection of onconeural antibodies has been extremely useful in indicating the presence of a tumour and defining a given neurological syndrome as paraneoplastic. However, PNS may occur without onconeural antibodies, and the antibodies can occur without a neurological syndrome; therefore, their presence should not be the only condition for defining a neurological syndrome as paraneoplastic.

As all PNS are rare, it is important to be able to pool data from different centres to define new onconeural antibodies and new syndromes. Besides, there is a lack of uniform criteria to diagnose some PNS. For these reasons, internationally accepted diagnostic criteria of PNS would be advantageous. In November 2002 an international panel of neurologists interested in the field of PNS began to establish guidelines to provide more rigorous diagnostic criteria for PNS. The aim was to assist neurologists in the diagnosis and classification of PNS, to allow comparison between series of patients from different centres, to facilitate the pooling of patients for clinical trials, and ultimately to identify new clinical and tumour associations. The study is supported by a grant from the European Union.

\section{METHODS}

The panel first considered the different syndromes known as paraneoplastic (table 1) and identified those defined as classical in previous studies. ${ }^{2}$ The panel decided not to include in this review the following syndromes: myasthenia gravis, paraproteinemic neuropathies, and paraneoplastic retinopathies because they are usually discussed in other clinical forums. The panel reviewed the existing diagnostic criteria of the different classical syndromes and recommended new criteria for those in whom no clinical consensus was reached in the past. Then, the panel reviewed all reported onconeural antibodies and established the conditions to identify those that would be labelled as well characterised. The antibody information was obtained from published work and from unpublished data from the different laboratories involved in the study. Anti-voltage gated calcium channel (VGCC) antibodies were not included in the list of onconeural antibodies, despite sharing some common features, because in the case of Lambert-Eaton myasthenic syndrome (LEMS) the antibody does not predict the presence of cancer.

On the basis of their discussion, the panel concluded that the diagnostic criteria of a neurological syndrome as paraneoplastic should be based on the presence or absence of cancer and the definitions of classical syndrome and well characterised onconeural antibody.

Abbreviations: LEMS, Lambert-Eaton myasthenic syndrome; PNS, paraneoplastic neurological syndrome; VGCC, voltage gated calcium channel. 
Table 1 Classical and non-classical paraneoplastic neurological syndromes

\begin{tabular}{|c|}
\hline Syndromes of the central nervous system \\
\hline $\begin{array}{l}\text { Encephalomyelitis } \\
\text { Limbic encephalitis } \\
\text { Brainstem encephalitis } \\
\text { Subacute cerebellar degeneration } \\
\text { Opsoclonus-myoclonus" } \\
\text { Optic neuritis† } \\
\text { Cancer associated retinopathy† } \\
\text { Melanoma associated retinopathy } \\
\text { Stiff person syndrome } \\
\text { Necrotising myelopathy } \ddagger \\
\text { Motor nuron diseases } \ddagger\end{array}$ \\
\hline Syndromes of the peripheral nervous system \\
\hline $\begin{array}{l}\text { Subacute sensory neuronopathy } \\
\text { Acute sensorimotor neuropathy } \\
\text { Guillain-Barré syndrome } \\
\text { Brachial neuritis } \\
\text { Subacute/chronic sensorimotor neuropathies* } \\
\text { Neuropathy and paraproteinaemia† } \\
\text { Neuropathy with vasculitis } \ddagger \\
\text { Autonomic neuropathies } \\
\text { Chronic gastrointestinal pseudo-obstruction } \\
\text { Acute pandysautonomiał }\end{array}$ \\
\hline Syndromes of the neuromuscular junction and muscle \\
\hline $\begin{array}{l}\text { Myasthenia gravis } \uparrow \\
\text { Lambert-Eaton myasthenic syndrome } \neq \\
\text { Acquired neuromyotonia } \\
\text { Dermatomyositis } \\
\text { Acute necrotising myopathy } \ddagger\end{array}$ \\
\hline
\end{tabular}

Classical syndromes are underlined.

*Associated with onconeural antibodies only with particular fumour types.

tSyndromes not included in the present recommendations.

¥Neurological syndromes not associated with known onconeural

antibodies.

\section{DEFINITIONS}

\section{Classical syndromes}

The term "classical syndrome" (table 1, underlined) applies to those neurological syndromes that often associate with cancer. The diagnosis of a classical syndrome should prompt the investigation of an occult tumour regardless of the antibody status. It is beyond the scope of this study to discuss which tests should be done to diagnose a presumably occult tumour or how often the test should be repeated. However, if a tumour is found during the work up that is not the one usually associated with the syndrome ${ }^{2}$ (see table 2 ), the panel recommends to keep looking for a second more typical tumour. If the PNS and "unusual" tumour is associated with onconeural antibodies, there should be attempts to show that the antigen is also expressed in the tumour. ${ }^{5}$

The panel identified several classical syndromes with previously reported reliable criteria. They included opsoclonusmyoclonus, ${ }^{6}$ LEMS, $^{7}$ and dermatomyositis. ${ }^{8}$ Chronic gastrointestinal pseudo-obstruction is a disorder initially seen by gastroenterologists and the panel decided to subscribe present diagnostic criteria although they are not unambiguously defined. ${ }^{9}$ For other classical syndromes the diagnostic criteria were not well defined or were not widely followed. The panel proposed the following criteria taking into account previous efforts done in this area.

\section{Encephalomyelitis}

Henson and colleagues introduced the term "encephalomyelitis with carcinoma" to define patients with cancer who developed clinical or pathological dysfunction of various parts of the nervous system. ${ }^{10}$ Subsequent studies showed that these patients may also show involvement of the peripheral nerves or the myenteric plexus indicating that the term "encephalomyelitis" does not include the full pathological spectrum of the syndrome. ${ }^{1}$ Although the terms "encephalomyeloneuritis" or "encephalomyeloneuropathy" were later proposed, they have not been routinely used. Another limitation of the term "encephalomyelitis" is that it does not provide information on the main clinical picture of the patient. The panel recommended use of the term "encephalomyelitis" to describe those patients with relevant clinical dysfunction at multiple levels of the central nervous system including the dorsal root ganglia or myenteric plexus (table 3). Even in this setting, the identification of the main neurological dysfunction should be provided whenever possible. The term "encephalomyelitis" should be avoided when there is prominent dysfunction of a single level of the nervous system. In these patients, the disorder should be described according to the focal syndrome that best includes the signs and symptoms (that is, brainstem encephalitis).

\section{Limbic encephalitis}

Limbic encephalitis is clinically suggested by the subacute onset, in days or up to 12 weeks, of seizures, short term memory loss, confusion, and psychiatric symptoms suggesting involvement of the limbic system. ${ }^{11}$ Definite diagnosis must also include either neuropathological or neuroradiological evidence (MR, SPECT, PET) of involvement of the limbic system. CSF evidence of inflammation is reported in $80 \%$ of limbic encephalitis and may be used to support the clinical diagnosis. ${ }^{11}$ The presence of high levels of voltage gated potassium channel (VGKC) antibodies may suggest the diagnosis of idiopathic limbic encephalitis ${ }^{12}$ but these antibodies are also found in a few patients with a paraneoplastic origin, ${ }^{13}$ so the test should not be used to exclude a paraneoplastic cause of the limbic encephalitis.

\section{Subacute cerebellar degeneration}

To define the cerebellar syndrome as classical, the following criteria are required: development in less than 12 weeks of a severe pancerebellar syndrome with no MR evidence of cerebellar atrophy other than that expected by the age of the patient. The severity of the cerebellar syndrome should cause a Rankin score of at least 3 (symptoms significantly interfere with lifestyle or prevent totally independent existence).

Predominant or isolated gait ataxia may be present in the first stage of the syndrome but clinical evidence of truncal and hemispheric cerebellar dysfunction is required for the diagnosis. The presence of symptoms or signs of involvement beyond the cerebellum is not uncommon and does not rule out the diagnosis. ${ }^{14}$ The coincidence with LEMS $^{15}$ or positive P/Q type VGCC antibodies, present in around $40 \%$ of patients with paraneoplastic cerebellar degeneration and lung cancer, ${ }^{16}$ further supports the paraneoplastic origin of the cerebellar syndrome.

\section{Sensory neuronopathy}

The term neuronopathy was introduced to describe a neurological syndrome characterised by primary damage of the nerve cell body. The diagnosis of classical sensory neuronopathy should be considered if all the following criteria are present ${ }^{17}{ }^{18}$ : subacute onset with a Rankin score of at least 3 before 12 weeks of evolution, onset of numbness, and often pain, marked asymmetry of symptoms at onset, involvement of the arms, proprioceptive loss in the areas affected, and electrophysiological studies that show marked, but not restricted, involvement of the sensory fibres with absent sensory nerve action potentials in at least one of the nerves studied.

Paraneoplastic sensory neuronopathy is not always an isolated syndrome and the neurological evaluation may 
Table 2 Onconeural antibodies

\begin{tabular}{|c|c|c|c|c|c|c|}
\hline Antibody & $\begin{array}{l}\text { No of } \\
\text { patients } \\
\text { reported }\end{array}$ & $\begin{array}{l}\text { Identified } \\
\text { by more } \\
\text { than one } \\
\text { laboratory }\end{array}$ & $\begin{array}{l}\text { Paraneoplastic neurological } \\
\text { syndrome }\end{array}$ & Tumours & $\begin{array}{l}\% \text { of antibody positive } \\
\text { patients without } \\
\text { cancer* (number of } \\
\text { patients studied) }\end{array}$ & $\begin{array}{l}\text { Frequency in cancer } \\
\text { patients without } \\
\text { PNS (number } \\
\text { studied) }\end{array}$ \\
\hline \multicolumn{7}{|c|}{ Well characterised onconeuronal antibodies } \\
\hline Anti-Hu (ANNA1) & $>600$ & Yes & $\begin{array}{l}\text { Encephalomyelitis; sensory } \\
\text { neuronopathy; chronic } \\
\text { gastrointestinal pseudo-obstruction; } \\
\text { paraneoplastic cerebellar } \\
\text { degeneration (PCD); limbic } \\
\text { encephalitis }\end{array}$ & $\begin{array}{l}\text { Small cell lung } \\
\text { cancer (SCLC) }\end{array}$ & $2 \%(200)^{5}$ & $\begin{array}{l}16 \% \text { (196 SCLC) (1\% } \\
\text { with titres similar to } \\
\text { those patients with } \\
\text { PNS) }\end{array}$ \\
\hline Anti-Yo (PCAl) & $>200$ & Yes & $\begin{array}{l}\text { Paraneoplastic cerebellar } \\
\text { degeneration }\end{array}$ & Ovary, breast & $2 \%(125)^{1423-25}$ & $1 \%(107)^{26}$ \\
\hline Anti-CV2 (CRMP5) & $>100$ & Yes & $\begin{array}{l}\text { Encephalomyelitis; chorea; } \\
\text { sensory neuronopathy; sensorimotor } \\
\text { neuropathy; chronic gastrointestinal } \\
\text { pseudo-obstruction; paraneoplastic } \\
\text { cerebellar degeneration; limbic } \\
\text { encephalitis }\end{array}$ & $\begin{array}{l}\text { SCLC, } \\
\text { thymoma }^{2728}\end{array}$ & $4 \%(47) \dagger$ & $9 \%(74 \mathrm{SCLC})^{29}$ \\
\hline Anti-Ri (ANNA2) & $61 \ddagger$ & Yes & Brainstem encephalitis & Breast, SCLC & $3 \%(61)^{30-34} \S$ & $\begin{array}{l}4 \%(181 \text { ovarian } \\
\text { cancer })^{35}\end{array}$ \\
\hline Anti-Ma2 (Ta) & 55 & Yes & $\begin{array}{l}\text { Limbic/diencephalic encephalitis; } \\
\text { brainstem encephalitis/PCD }\end{array}$ & Testicular, lung & $4 \%(55)^{36}$ & $0 \%(350)$ \\
\hline Anti-amphiphysin & $20 \ddagger$ & Yes & $\begin{array}{l}\text { Stiff person syndrome; various } \\
\text { syndromes }\end{array}$ & Breast SCLC & $5 \%(20)^{3738}$ & $\begin{array}{l}0 \%(25 \\
\text { gynaecological } \\
{\text { cancer })^{39}}^{40}(146 \\
\mathrm{SCLC}^{40}\end{array}$ \\
\hline \multicolumn{7}{|c|}{ Partially characterised onconeuronal antibodies } \\
\hline Anti-Tr (PCA-Tr) & 28 & Yes & $\begin{array}{l}\text { Paraneoplastic cerebellar } \\
\text { degeneration }\end{array}$ & $\begin{array}{l}\text { Hodgkin's } \\
\text { disease }\end{array}$ & $11 \%(28)^{41 * *}$ & $0 \%(30)^{42}$ \\
\hline ANNA3 & 11 & No & Various syndromes & SCLC & $9 \%(11)^{43}$ & $0 \%(58)^{43}$ \\
\hline PCA2 & 9 & No & Various syndromes & $\mathrm{SCLC}$ & $0 \%(8)^{44}$ & $2 \%(58)^{44}$ \\
\hline Anti-Zic4 & 8 & No & $\begin{array}{l}\text { Paraneoplastic cerebellar } \\
\text { degeneration }\end{array}$ & $\mathrm{SCLC}$ & $12 \%(8)^{29}$ & $16 \%(74)^{29}$ \\
\hline Anti-mGluR1 & 2 & No & $\begin{array}{l}\text { Paraneoplastic cerebellar } \\
\text { degeneration }\end{array}$ & $\begin{array}{l}\text { Hodgkin's } \\
\text { disease }\end{array}$ & $50 \%(2)^{45}$ & $?$ \\
\hline
\end{tabular}

demonstrate involvement of the motor nerves, peripheral autonomic nervous system, or different areas of the brain (encephalomyelitis). ${ }^{15}$ The panel recommends to keep the diagnosis of classical sensory neuronopathy if the criteria described above are fulfilled, even if there is minor involvement of motor nerves or other areas of the nervous system elicited by clinical or paraclinical examinations.

Some patients present with sensory symptoms compatible with the definition of sensory neuronopathy, but also show severe motor weakness that may be caused by involvement of motorneurons in the anterior horn of the spinal cord ${ }^{19}$ or the peripheral nerves. ${ }^{20}{ }^{21}$ These syndromes occur usually associated with SCLC and positive anti-Hu or CV2 antibodies. In this setting, if the clinical or electrophysiological examination suggest involvement of the dorsal root ganglia, the panel

Table 3 Main clinical syndromes observed in encephalomyelitis

\begin{tabular}{ll}
\hline Syndrome & Pathological involvement \\
\hline Limbic encephalitis & Hippocampus, amygdala \\
Brainstem encephalitis (predominantly & Medulla oblongata \\
bulbar) & Purkinje cells \\
Cerebellar degeneration & Motor neurons \\
Myelitis (anterior horn) & Dorsal root ganglia \\
Sensory neuronopathy & Myenteric plexus \\
Chronic gastrointestinal pseudo-obstruction & \\
\hline
\end{tabular}

recommends to use the term sensory neuronopathy with motor involvement, rather than sensorimotor neuropathy that would imply a primary damage restricted to the peripheral nerve.

\section{Well characterised onconeural antibodies}

Onconeural antibodies are found in patients with cancer and different types of PNS. ${ }^{4}$ There are several limitations that neurologists must be aware when using the onconeural antibodies in the diagnosis of PNS (table 2). Firstly, some antibodies have been described by a single group of investigators or reported in only a few patients. Secondly, although most onconeural antibodies described appear to be specific for PNS, a few patients never develop cancer after a follow up of several years.

The panel decided that, in the absence of a detected tumour, only well characterised onconeural antibodies (anti-Hu, Yo, CV2, Ri, Ma2, amphiphysin) should be used to classify the associated disorder as definite PNS. The term well characterised antibodies is based upon (1) antibodies for which there are recognisable patterns on routine immunohistochemistry and for which immunoblotting on recombinant proteins must be used to confirm their specificities; (2) the number of cases reported associated with tumours; (3) the description of well characterised neurological syndromes associated with the antibodies; (4) the unambiguous identification of the antibodies among different studies, and (5) the frequency of these antibodies in patients without cancer. Future studies will probably allow upgrading the 
partially characterised onconeural antibodies (anti-Tr, ANNA3, PCA2, Zic4, and mGluR1) to the group of well characterised antibodies. Other antineuronal antibodies occasionally detected in one or a few patients with PNS should not be used in the diagnosis of PNS until more data are obtained.

\section{Diagnostic criteria for PNS}

Based on these considerations, the panel suggested that there should be two levels of diagnostic evidence to define a neurological syndrome as paraneoplastic: "definite" and "possible". Each level can be reached combining a set of criteria (table 4, fig 1). The panel recognises that the term "possible" may include true PNS but also the coincidental association of two unrelated disorders (the neurological syndrome and cancer). However, this level of evidence may be useful to identify disorders that in the future may be upgraded to definite PNS and to recognise PNS based on the identification of specific trends, such as a higher than expected association with a specific type of cancer. The panel emphasises that definite and possible PNS have in common the need to exclude other known causes that could explain the neurological syndrome under study even if onconeural antibodies are positive.

\section{Criteria for definite PNS}

1. A classical syndrome and cancer that develops within five years of the diagnosis of the neurological disorder

In this setting, the presence of onconeural antibodies is not required. A neurological syndrome will be diagnosed as classical if it is one of those underlined in table 1 and also fulfils the diagnostic criteria suggested in these recommendations. The time period of five years is based on previous work that shows that in patients with classical syndromes the tumour is almost always diagnosed within five years after the onset of the PNS. ${ }^{5} 723$

2. A non-classical syndrome that resolves or significantly improves after cancer treatment without concomitant immunotherapy, provided that the syndrome is not susceptible to spontaneous remission

The panel strongly recommends using objective measures to document the improvement of the clinical syndrome. The
Table 4 Diagnostic criteria for paraneoplastic neurological syndromes (PNS)

Definite PNS

1. A classical syndrome and cancer that develops within five years of the diagnosis of the neurological disorder.

2. A non-classical syndrome that resolves or significantly improves after cancer treatment without concomitant immunotherapy, provided that the syndrome is not susceptible to spontaneous remission.

3. A non-classical syndrome with onconeural antibodies (well

characterised or not) and cancer that develops within five years of the

diagnosis of the neurological disorder.

4. A neurological syndrome (classical or not) with well characterised onconeural antibodies (anti-Hu, Yo, CV2, Ri, Ma2, or amphiphysin), and no cancer

Possible PNS

1. A classical syndrome, no onconeural antibodies, no cancer but at high risk to have an underlying tumour.

2. A neurological syndrome (classical or not) with partially characterised onconeural antibodies and no cancer.

3. A non-classical syndrome, no onconeural antibodies, and cancer present within two years of diagnosis.

panel recognises that a stabilisation of the neurological syndrome may represent a response to tumour treatment with no further improvement noted due to irreversible neuronal damage. However, the neurological deficits of some syndromes may have reached a plateau or stabilise by the time the tumour is treated. This may lead to the impression that tumour treatment and stabilisation are related. The diagnosis of definite PNS should not apply to patients whose tumour treatment includes drugs that also are immunosuppressive and known to improve the associated neurological syndrome.

3. A non-classical syndrome with onconeural antibodies (well characterised or not) and cancer that develops within five years of the diagnosis of the neurological disorder

The inclusion in the definition of non-classical neurological syndromes may allow the identification of previously unrecognised PNS (such as chorea ${ }^{46}$ ) or upgrade as definite neurological syndromes that do not fulfil all the requirements

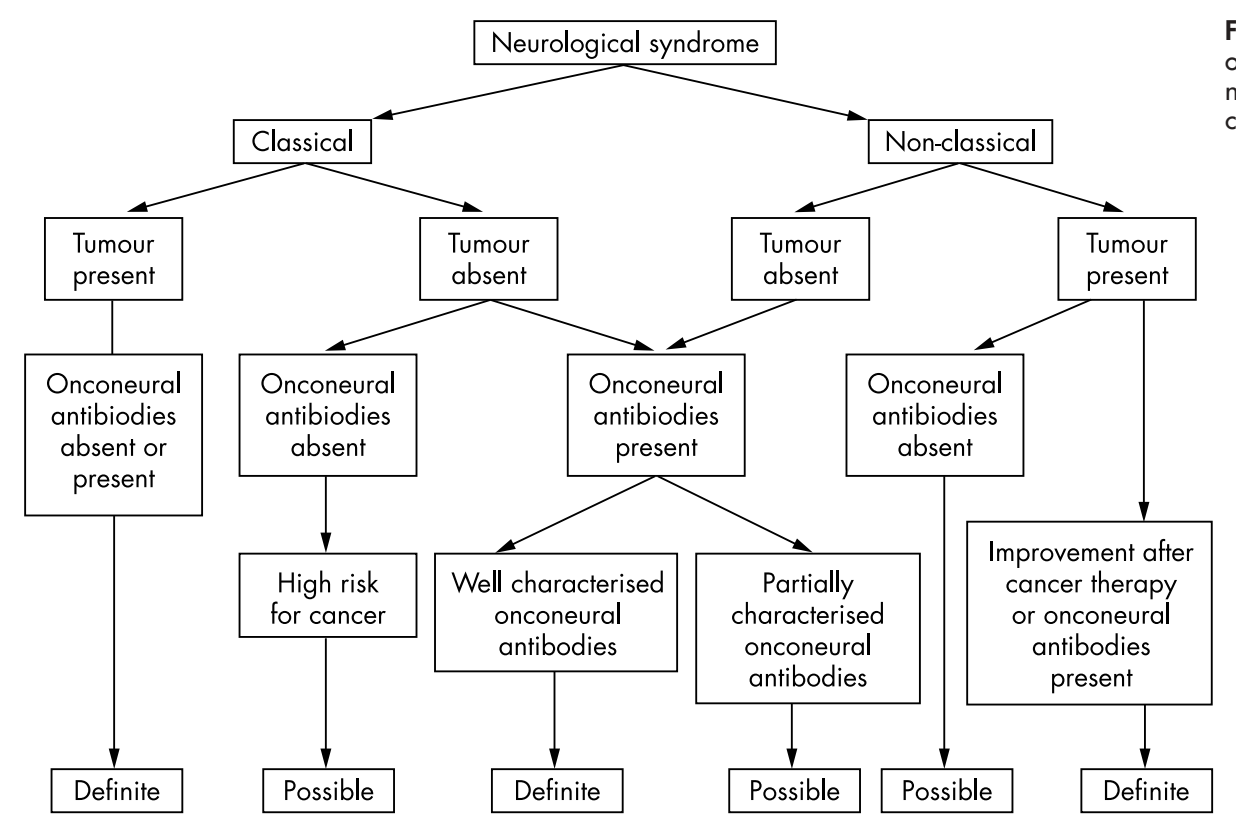

Figure 1 Flow chart showing the level of diagnostic evidence of the neurological syndrome according to the criteria defined by the panel. 
to define them as classical (such as indolent sensory neuronopathies ${ }^{47}$ ) provided they are associated with onconeural antibodies.

4. A neurological syndrome (classical or not) with well characterised onconeural antibodies (anti-Hu, Yo, CV2, Ri, Ma2, or amphiphysin), and no cancer The panel recognises that this set of criteria may include a very small number of false positive cases that will never develop cancer in spite of the presence of well characterised onconeural antibodies (table 2). A plausible explanation is that the tumour was eliminated by the immune response. ${ }^{4}$ Despite this limitation, the clinical data associated with these antibodies are robust enough to consider for practical purposes any patient who harbours well characterised onconeural antibodies as a carrier of a PNS and almost all reported patients have developed a cancer. By contrast, antiTr antibodies cannot be used to classify the PNS as definite in the absence of cancer because $11 \%(3 / 28)$ of patients reported never developed Hodgkin's disease and the antibody disappeared during the follow up. ${ }^{41}$

\section{Criteria for possible PNS}

1. A classical syndrome, no onconeural antibodies, no cancer but at high risk to have an underlying tumour

Some classical syndromes are not associated with onconeural antibodies and may also occur in absence of cancer. The diagnosis of cancer during the follow up is the only way to define the syndrome as definite PNS. All these patients should have at least an initial work up for cancer. If cancer never develops after five years, the syndrome should be removed from the possible PNS category.

Presently, there are no clear clinical or biological markers that predict if the neurological syndrome, for example LEMS, is associated with cancer or not. However, there are some clues that may help neurologists to predict which patients with these classical syndromes are at high risk to have an underlying cancer (table 5). The panel's recommendation is that the diagnosis of possible PNS, in the setting of the present set of criteria, should apply only to those classical syndromes that also have the identified risks for an underlying tumour

2. A neurological syndrome (classical or not) with partially characterised onconeural antibodies and no cancer

Although the clinical information associated with partially characterised onconeural antibodies is limited, the present data suggest these onconeural antibodies are rarely seen in patients without cancer. Therefore, the neurological syndromes that fulfil the criteria defined above should be considered possible PNS until the follow up confirms or not the presence of an underlying tumour.

Table 5 Clinical and biological clues that indicated an elevated risk of cancer in patients with classical syndromes and no onconeural antibodies

\begin{tabular}{ll}
\hline Syndrome & Clues \\
\hline Limbic encephalitis & $\begin{array}{l}\text { Negative VGKC antibodies and no } \\
\text { recovery with immunotherapy }\end{array}$ \\
Subacute cerebellar degeneration & $\begin{array}{l}\text { Positive VGCC antibodies or } \\
\text { association with LEMS }\end{array}$ \\
Opsoclonus-myoclonus syndrome & $\begin{array}{l}\text { Age }<5 \text { or }>40 \text { years or no } \\
\text { recovery with immunotherapy }\end{array}$ \\
Sensory neuronopathy & Age $>40$ years and smoking habit \\
LEMS & Age $>40$ years and smoking habit \\
Dermatomyositis & Age $>40$ years \\
\hline
\end{tabular}

3. A non-classical neurological syndrome, no onconeural antibodies, and cancer present within two years of diagnosis

This definition probably will include neurological syndromes in which we cannot rule out a casual association with as common an event as cancer. To minimise false positive diagnosis of possible PNS, the panel decided to limit the time period between the neurological syndrome and the diagnosis of cancer to two years.

Although some cases of sensorimotor neuropathy were considered potential PNS early in the description of these syndromes, they are clinically and neurophysiologically heterogeneous and associated with different tumour types. ${ }^{48}$ This heterogeneity raises the possibility that, at least in some situations, the coexistence of a neuropathy and cancer is coincidental. The recommendation of the panel is to define the neuropathy according to accepted criteria (that is, Guillain-Barré syndrome or chronic inflammatory demyelinating polyneuropathy) or to classify it as primary axonal or demyelinating, ${ }^{49}$ or prove the presence of microvasculitis. ${ }^{50}$ This approach may help to identify those neuropathies that more likely improve with immunotherapies, and to uncover or confirm specific associations between particular neuropathies and tumour types.

\section{Final comments}

Paraneoplastic neurological syndromes are rare disorders and even neurologists interested in the field personally examine only a few patients per year. The information collected from referring neurologists may miss detailed clinical or paraclinical information that may be important for a better definition of PNS. The present diagnostic criteria may help neurologists to report their patients with PNS more uniformly. The neuroimmunological research in PNS is a field in rapid evolution but at the same time with important limitations. For instance, the methodology to detect onconeural antibodies is not widely standardised, and with the discovery of new onconeural antibodies care must be taken to differentiate those that preferentially associate with PNS from those that may just reflect an antitumour immune response. Despite these limitations, the present recommendations on the diagnosis of PNS represent an attempt to clarify unresolved issues in this field. The future will prove if these recommendations have been useful to improve the diagnostic accuracy and research of PNS.

\section{ACKNOWLEDGEMENTS}

This study was supported by grant QLG1-CT-2002-01756 of the European Union.

\section{OTHER MEMBERS OF THE PARANEOPLASTIC NEUROLOGICAL SYNDROME EURONETWORK}

G Bertolin, Clinical Epidemiology laboratory, Instituto Mario Negri, Bergamo, Italy; A Carpentier, Service of Neurology, Hôpital de la Salpêtrière, Paris, France; L Lorusso, Department of Neurology, Chiari (Brescia), Italy; I K Hart, Neuroimmunology Group, Department of Neurological Science, Liverpool, UK; J Peltola. Department of Pathology, Tampere, Finland; T Ros, Institute of Oncology, Medical Oncology/Neurology, Ljubljana, Slovenia; F Scaravilli, Division of Neuropathology, Institute of Neurology, UCL Queen Square, London, UK; P Stourac, Department of Neurology, Neuroimmunology Laboratory, Brno, Czech Republic; P A Tonali, Istituto di Neurologia, Università Cattolica Sacro Cuore, Rome, Italy; M C Vigliani. Department of Neuroscienze, Torino, Italy.

\section{Authors' affiliations}

F Graus, Service of Neurology, Institut d'Investigació Biomèdica August $\mathrm{Pi}$ i Sunyer (IDIBAPS), Hospital Clínic, University of Barcelona. Barcelona, Spain

J Y Delattre, Service of Neurology, Hôpital de la Salpêtrière, Unité Inserm 495, Paris, France 
J C Antoine, Department of Neurology, Hôpital Bellevue, Saint Etienne, France

J Dalmau, Department of Neurology, University of Pennsylvania,

Philadelphia, USA

B Giometto, Department of Neurology and Psychiatry (2 Neurologic Clinic), University of Padua, Padua, Italy

W Grisold, Ludwig Boltzmann Institut für Neuroonkologie, Vienna, Linz, Austria

J Honnorat, Ataxia Research Center, Neurology B, Hôpital

Neurologique, Lyon, France

P Sillevis Smitt, Department of Neurology, Erasmus University Medical Center, Rotterdam, The Netherlands

Ch Vedeler, Department of Neurology, Haukeland University Hospital, Bergen, Norway

J J G M Verschuuren, Department of Neurology, Leiden University Medical Center, Leiden, The Netherlands

A Vincent, Neurosciences Group, Institute of Molecular Medicine, John Radcliffe Hospital, Oxford, UK

R Voltz, Institute of Clinical Neuroimmunology. University of Munich, Munich, Germany

\section{REFERENCES}

1 Henson RA, Urich H. Part III. Paraneoplastic disorders. In: Henson RA, Urich H, eds. Cancer and the nervous system. Oxford: Blackwell Scientific Publications, 1982:311-451

2 Posner JB. Neurologic complications of cancer. Philadelphia, PA: FA Davis Company, 1995:353-84.

3 Darnell RB. Onconeural antigens and paraneoplastic neurologic disorders: At the intersection of cancer, immunity, and the brain. Proc Natl Acad Sci U S A 1996;93:4529-36.

4 Darnell RB, Posner JB. Paraneoplastic syndromes involving the nervous system. N Engl J Med 2003;349:1543-54.

5 Graus F, Keime-Guibert F, Reñé R, et al. Anti-Hu-associated paraneoplastic encephalomyelitis: analysis of 200 patients. Brain 2001;124:1138-48.

6 Anderson NE, Budde-Steffen C, Rosenblum MK, et al. Opsoclonus, myoclonus, ataxia and encephalopathy in adults with cancer: A distinct paraneoplastic syndrome. Medicine 1988;67:100-9.

7 O'Neill JH, Murray NMF, Newsom-Davis J. The Lambert-Eaton myasthenic syndrome. Brain 1988;111:577-96.

8 Bohan A, Peter JB, Bowman RL, et al. Computer-assisted analysis of 153 patients with polymyositis and dermatomyositis. Medicine 1977;56:255-86.

9 Chinn JS, Schuffler MD. Paraneoplastic visceral neuropathy as a cause of severe gastrointestinal motor dysfunction. Gastroenterology 1988;95:1279-86.

10 Henson RA, Hoffman HL, Urich H. Encephalomyelitis with carcinoma. Brain 1965;88:449-64.

11 Gultekin SH, Rosenfeld MR, Voltz R, et al. Paraneoplastic limbic encephalitis: neurological symptoms, immunological findings and tumour association in 50 patients. Brain 2000;123:1481-94.

12 Vincent A, Buckley C, Schott JM, et al. Potassium channel antibody-associated encephalopathy: a potentially immunotherapy-responsive form of limbic encephalitis. Brain 2004;127:701-12.

13 Pozo-Rosich P, Clover L, Saiz A, et al. Voltage-gated potassium channel antibodies in limbic encephalitis. Ann Neurol 2003;54:530-3.

14 Shams'ili S, Grefkens J, de Leeuw B, et al. Paraneoplastic cerebellar degeneration associated with antineuronal antibodies:analysis of 50 patients. Brain 2003;126:1409-18.

15 Mason WP, Graus F, Lang B, et al. Small-cell lung cancer, paraneoplastic cerebellar degeneration and the Lambert-Eaton mysthenic syndrome. Brain 1997; 120:1279-300

16 Graus F, Lang B, Pozo-Rosich P, et al. P/Q type calcium-channel antibodies in paraneoplastic cerebellar degeneration with lung cancer. Neurology 2002;59:764-6.

17 Horwich MS, Cho L, Porro RS, et al. Subacute sensory neuropathy: a remote effect of carcinoma. Ann Neurol 1977;2:7-19.

18 Chalk CH, Windebank AJ, Kimmel DW, et al. The distinctive clinical features of paraneoplastic sensory neuronopathy. Can J Neurol Sci 1992;19:346-51.

19 Graus F, Elkon KB, Lloberes $\mathrm{P}$, et al. Neuronal aninuclear antibody (anti-Hu) in paraneoplastic encephalomyelitis simulating acute polyneuritis. Acta Neurol Scan 1987;75:249-52.

20 Antoine JC, Mosnier JF, Honnorat J, et al. Paraneoplastic demyelinating neuropathy, subacute sensory neuropathy, and anti-Hu antibodies: clinicopathological study of an autopsy case. Muscle Nerve 1998;21:850-7.
21 Camdessanché JP, Antoine JC, Honnorat J, et al. Paraneoplastic peripheral neuropathy associated with anti-Hu antibodies. A clinical and electrophysiological study of 20 patients. Brain 2002;125:166-75

22 Graus F, Dalmau R, Reñé R, et al. Anti-Hu antibodies in patients with small-cell lung cancer: Association with complete response to therapy and improved survival. J Clin Oncol 1997;15:2866-72.

23 Peterson K, Rosenblum MK, Posner JB. Paraneoplastic cerebellar degeneration: a clinical analysis of 55 anti-Yo antibody-positive patients. Neurology 1992:42:1931-7.

24 Rojas I, Graus F, Keime-Guibert F, et al. Long-term clinical outcome of paraneoplastic cerebellar degeneration and anti-Yo antibodies. Neurology 2000;55:713-5.

25 Rojas-Marcos I, Rousseau A, Keime-Guibert F, et al. Spectrum of paraneoplastic neurological disorders in women with breast and gynaecological cancer. Medicine 2003;82:216-33.

26 Liu S, Mezrich J, Berk, et al. Expression of Purkinje-cell antigens in ovarian tumor and presence of anti-Purkinje cell antibodies in the serum of patients without paraneoplastic cerebellar degeneration. Neurology 1995;45:228.

27 Honnorat J, Antoine JC, Derrington E, et al. Antibodies to a subpopulation of glial cells and a $66 \mathrm{Kd}$ developmental protein in patients with paraneoplastic neurological síndromes. J Neurol Neurosurg Psychiatry 1996;61:270-8.

28 Yu Z, Kryzer TJ, Griesmann GE, et al. CRMP-5 neuronal autoantibody: marker of lung cancer and thymoma-related autoimmunity. Ann Neurol 2001:49:146-54.

29 Bataller L, Wade DF, Graus F, et al. Antibodies to Zic4 in paraneoplastic neurologic syndromes and small-cell lung cancer. Neurology 2004;62:138-40.

30 Dropcho EJ, Kline LB, Riser J. Antineuronal (anti-Ri) antibodies in a patient with steroid-responsive opsoclonus-myoclonus. Neurology 1993:43:207-11.

31 Hormigo A, Dalmau J, Rosenblum MK, et al. Immunological and pathological study of anti-Ri-associated encephalopathy. Ann Neurol 1994;36:896-902.

32 Sutton IJ, Barnett MH, Watson JDG, et al. Paraneoplastic brainstem encephalitis and anti-Ri antibodies. J Neurol 2002;249:1597-8.

33 Pittock SJ, Lucchinetti CF, Lennon VA. Anti-neuronal nuclear autoantibody type-2: paraneoplastic accompaniments. Ann Neurol 2003;53:580-7.

34 Angstwurm K, Schielke E, Zimmer C, et al. Superficial siderosis of the central nervous system: response to steroid therapy. J Neurol 2000;249:1223-25.

35 Drlicek M, Bianchi G, Bogliun G, et al. Antibodies of the anti-Yo and anti-Ri type in the absence of paraneoplastic neurological syndromes: a long-term survey of ovarian cancer patients. J Neurol 1997;244:85-9.

36 Rosenfeld MR, Eichen JG, Wade DF, et al. Molecular and clinical diversity in paraneoplastic immunity to Ma proteins. Ann Neurol 2001;50:339-48.

37 Folli $F$, Solimena $M$, Cofiell $R$, et al. Autoantibodies to a 128-kd synaptic protein in three women with the stiff-man syndrome and breast cancer. N Engl J Med 1993;328:546-51.

38 Prego L, Previtali SC, Nemni R, et al. Autoantibodies to amphiphysin I and amphiphysin II in a patient with sensory-motor neuropathy. Eur Neurol 2002; 47:196-200

39 Antoine JC, Absi L, Honnorat J, et al. Antiamphiphysin antibodies are associated with various paraneoplastic neurological syndromes and tumors. Arch Neurol 1999;56:172-7.

40 Saiz A, Dalmau J, Butler MH, et al. Anti-amphiphysin I antibodies in patients with paraneoplastic neurologic disorders associated with small cell lung carcinoma. J Neurol Neurosurg Psychiatry 1999;66:214-17.

41 Bernal F, Shams'ili S, Rojas I, et al. Anti-Tr antibodies as markers of paraneoplastic cerebellar degeneration and Hodgkin's disease. Neurology 2003;60:230-4.

42 Graus F, Dalmau J, Valldeoriola F, et al. Immunological characterization of a neuronal antibody (anti-Tr) associated with paraneoplastic cerebellar degeneration and Hodgkin's disease. J Neuroimmunol 1997;74:55-61.

43 Chan KH, Vernino S, Lennon VA. ANNA-3 anti-neuronal nuclear antibody: marker of lung cancer-related autoimmunity. Ann Neurol 2001;50:301-11.

44 Vernino S, Lennon VA. New Purkinje cell antibody (PCA-2): marker of lung cancer-related neurological autoimmunity. Ann Neurol 2000;47:297-305.

45 Sillevis Smitt P, Kinoshita A, De Leeuw B, et al. Paraneoplastic cerebellar ataxia due to autoantibodies against a glutamate receptor. $N$ Engl J Med 2000;342:21-7.

46 Vernino S, Tuite $\mathrm{P}$, Adler $\mathrm{Ch}$, et al. Paraneoplastic chorea associated with CRMP-5 neuronal antibody and lung carcinoma. Ann Neurol 2002:51:625-30.

47 Graus $\mathrm{F}$, Bonaventura I, Uchuya $M$, et al. Indolent anti-Hu-associated paraneoplastic sensory neuropathy. Neurology 1994;44:2258-61.

48 Croft PB, Urich H, Wilkinson M. Peripheral neuropathy of sensorimotor type associated with malignant disease. Brain 1967;90:31-65.

49 Antoine JC, Mosnier JF, Lapras J, et al. Chronic inflammatory demyelinating polyneuropathy associated with carcinoma. I Neurol Neurosurg Psychiatry 1996;60:188-90.

50 Oh SJ, Slaughter R, Harrell L. Paraneoplastic vasculitic neuropathy: a treatable neuropathy. Muscle Nerve 1991;14:152-6. 